\title{
Infecções do esterno pós revascularização do miocárdio: tratamento com retalhos miocutâneos e musculares
}

\author{
Rubens T. de BARROS*, Mauro A. de MARCHI**, Fábio V. GUIMARÃES FILHO^, Wesley F. da SILVEIRA*, \\ Hugo V. C. JIMENEZ ${ }^{* * *}$, Antônio PENNA JÚNIOR*
}

BARROS, R. T.; MARCHI, M. A.; GUIMARÃES FILHO, F. V.; SILVEIRA, W. F.; JIMENEZ, H. V. C.; PENNA JÚNIOR, A. - Infecçōes do esterno pós revascularização do miocárdio: tratamento com retalhos miocutâneos e musculares. Rev. Bras. Cir. Cardiovasc., 4(2): 151-158, 1989.

RESUMO: No período de outubro de 1986 a janeiro de 1989, realizamos 445 esternotomias, sendo 158 para revascularizaçāo do miocárdio; em 92 pacientes, a artéria mamária interna esquerda (AMIE) foi utilizada. Dos 445 casos, sete pacientes tiveram infecção do esterno no período pós-operatório imediato. O tempo médio de aparecimento foi de 8,7 dias (4-15 dias), sendo que seis pacientes eram do sexo masculino e a idade média foi de 48,8 anos (35-60 anos). Em todos os casos, os pacientes estavam sendo submetidos à primeira cirurgia, tendo como possiveis fatores associados diabete (um caso), embolia pulmonar com insuficiência respiratória (um caso), síndrome de baixo débito (três casos), cirurgia prolongada (um caso) e dissecção da AMIE (seis casos). Na correção desta complicação, a associação de técnicas de cirurgia plástica, com a utilização de retalhos miocutâneos ou musculares, permitiu mais rápida recuperação dos pacientes, sem que tivéssemos óbitos nesta série. Os resultados estético e funcional foram considerados excelentes, com três pequenas deiscências tratadas ambulatorialmente. A identificação do germe através de cultura e a orientaçāo do tratamento pelo antibiograma também se mostraram de grande importância, ao lado das técnicas cirúrgicas empregadas. Concluindo, julgamos que a intervenção precoce e agressiva nas infecçōes do esterno contribuiu, efetivamente, na queda da morbi-mortalidade desta complicaçāo.

DESCRITORES: esterno, infecçōes; miocárdio, revascularização, complicações.

\section{INTRODUÇĀO}

A cirurgia do coração recebeu grande contribuição, em 1956, quando JULIAN et alii ${ }^{6}$ propuseram a técnica de secção longitudinal do esterno, via de acesso que oferece excelente exposição dos órgãos mediastinais. Desde aquela época, a infecção óssea, com possibilidade de se estender aos tecidos circunvizinhos, tem preocupado a todos os cirurgiōes que se utilizam desta incisão. Apesar de infreqüente, é uma situação que, quando ocorre, pode cursar com mediastinite, que, ao atingir o coraçăo e suas suturas, próteses e enxertos, leva a complicaçōes, não poucas vezes letais.

A maioria dos autores ${ }^{4},{ }^{112}, 13$ concorda em que cerca de $2 \%$ das esternotomias acabam por se infectar e, neste casos, observa-se elevada morbi-mortalidade, com longos períodos de internação hospitalar, cirurgias repetidas, necessidade de utilização maciça de antibióticos e elevado custo de tratamento.

Visando atenuar estes fatos, em 1963, SHUMAKER Jr. \& MANDELBAUM ${ }^{16}$ propuseram a clássica técnica

Trabalho realizado na Irmandade da Santa Casa de Misericórdia de Marilia, no Instituto de Cardiologia de Marilia e na Clínica de Cirurgia Plástica, Marilia, SP, Brasil.

- Do Instituto de Cardiologia de Marilia

** Da Clínica de Cirurgia Plástica.

*** Da Irmandade da Santa Casa de Misericórdia de Marilia.

Endereço para separatas: Rubens T, de Barros. Av. Rio Branco, 1173. 17500 Marilia, SP, Brasil. 
BARROS, R. T.; MARCHI, M. A.; GUIMARÃES FILHO, F. V.; SILVEIRA, W. F.; JIMENEZ, H. V. C.; PENNA JÚNIOR, A. - Infecçōes do esterno pós revascularização do miocárdio: tratamento com retalhos miocutâneos e musculares. Rev. Bras. Cir. Cardiovasc., $4(2): 151-158,1989$.

de irrigação mediastinal com agentes antimicrobianos que, efetivamente, contribuiu para melhorar o atendimento a estes pacientes. Todavia, ainda assim, o índice de insucessos permanece elevado, com grande número de óbitos.

Em 1979, surgiram os primeiros trabalhos de ARNOLD \& PAIROLERO ${ }^{2}$, que mostravam a possibilidade de se utilizarem retalhos miocutâneos ou musculares na reparaçāo das infecçōes do esterno, mais especificamente nos casos em que este osso e as cartilagens costais eram ressecados.

Em conjunto com o Serviço de Cirurgia Plástica, a partir de outubro de 1986, passamos a empregar técnicas de reconstruçāo da parede torácica com a utilizaçāo de retalhos miocutâneos ou musculares, cujos resultados são o objetivo do presente trabalho.

\section{CASUISTICA E MÉTODOS}

No período de outubro de 1986 a janeiro de 1989 , 445 pacientes foram submetidos a esternotomia mediana, em nosso Serviço. Destes, 158 foram submetidos a revascularizaçāo do miocárdio, sendo que, em 92 pacientes, a artéria mamária interna esquerda foi utilizada, predominantemente, na revascularização da artéria descendente anterior. Neste grupo, sete pacientes evoluíram com infecçāo do esterno, o que representa uma incidência global de $1,57 \%$, número que sobe para $4,43 \%$ quando analisamos apenas os coronariopatas e, mais ainda, para $7,60 \%$ se observarmos apenas aqueles que tiveram dissecção da AMIE.

Todos os pacientes estavam sendo submetidos à sua primeira esternotomia, sendo que o aparecimento da infecção, caracterizada por hiperemia, dor local, febre, secreção purulenta e instabilidade óssea com ou sem deiscência, foi em média de 8,7 dias após a cirurgia, com o mínimo de quatro e o máximo de 15 dias.

Seis pacientes eram do sexo masculino e a idade variou de 35 a 60 anos, com média de 48,8 anos. Além da dissecção da artéria mamária interna esquerda (AMIE) (seis casos), observamos, como fatores associados, a síndrome de baixo débito em três casos, diabetes mellitus um caso, embolia pulmonar com necessidade de ventilação mecânica em um caso e cirurgia longa com tempo prolongado de circulação extracorpórea em um caso. Não tivemos reoperaçōes no período imediato.

Em todos os casos, a cultura da secreção foi positiva, sendo que, em quatro casos tivemos $\mathbf{S}$. aureus, em dois tivemos S. epidermidis e em um, E. coli.

Em todos os pacientes, a aproximaçāo do esterno foi realizada com fios de aço, sendo dois fios transfixando o manúbrio e seis outros nos espaços intercostais, sem transfixar costelas ou cartilagens.
Quando da infecção, em um primeiro tempo, realizamos a limpeza cirúrgica sob anestesia geral, com especial ênfase ao desbridamento do esterno, costelas e cartilagens, até que obtivéssemos um tecido realmente sadio, sem quaisquer evidências de infecção, com boa vitalidade evidenciada pelo sangramento e pela coloração do tecido. Em dois pacientes, tivemos que ressecar, totalmente, o esterno, à exceçāo de pequena porção do manúbrio. Ao mesmo tempo, retiramos todo e qualquer corpo estranho e tecido desvitalizado, evitando atingir o mediastino, que estava bloqueado em seis pacientes. Em um dos casos, havia mediastinite associada, o que nos obrigou a drenar as várias lojas que se formaram.

Após esta limpeza, os pacientes foram mantidos com curativos de iodo povidine, trocados duas a três vezes ao dia, por um período médio de sete dias. Durante este período, pudemos acompanhar o aparecimento do tecido de granulação e, se necessário, complementar a limpeza inicial. Nesta fase, apenas um paciente necessitou de assistência ventilatória, pois recuperava-se de embolia pulmonar.

Assim que observávamos tecido de granulação adequado e, paralelamente, tínhamos uma evolução clínica sem complicações, os pacientes eram reoperados, para reparação dos tecidos expostos.

De acordo com a extensão da área exposta e o tamanho do espaço morto a ser coberto, utilizamos, em um paciente, um retalho fáscio-cutâneo bilateral; em três, a correçāo exigiu retalho miocutâneo peitoral bilateral e, nos outros três que tiveram maior ressecção óssea, a opção recaiu sobre a associação dos retalhos musculares, utilizando o peitoral maior esquerdo e reto do abdomen direito.

\section{RESULTADOS}

Em todos os casos, tivemos boa cicatrização com estabilidade do gradil costal remanescente, sem limitação da capacidade ventilatória e ausência de hérnias abdominais.

A recuperação estética e funcional foi classificada como excelente, pois todos os pacientes puderam retornar às suas atividades pré-operatórias, exceto o último, que se encontra em fase inicial de pós-operatório.

Em três pacientes, um de cada técnica, tivemos pequenas deiscências, que foram tratadas ambulatorialmente.

O tempo médio de hospitalizaçāo, após o desbridamento, foi de 18 dias. Sem que tivéssemos outras intercorrências.

Embora não tenhamos conseguido confirmar, através de culturas, os quatro primeiros casos desta série ocorreram em um periodo de dois meses, que coincidiu 
BARROS, R. T.; MARCHI, M. A.; GUIMARĀES FILHO, F. V.; SILVEIRA, W. F.; JIMENEZ, H. V. C.; PENNA JÚNIOR, A. - Infecçōes do esterno pós revascularização do miocárdio: tratamento com retalhos miocutâneos e musculares. Rev. Bras. Cir. Cardiovasc., 4(2): 151-158, 1989.

com a troca de material de sutura até então utilizado no tecido subcutâneo por outro, que suspeitamos estar contaminado (Figura 1)

\section{DISCUSSĀO}

A esternotomia mediana é a via de acesso preferencial para procedimentos que visam atingir o mediastino anterior e, principalmente, nas cirurgias do coração. Fácil de se realizar, de execuçăo rápida quando comparada a outras vias de acesso, apresenta uma baixa incidência de complicações. Porém, dentre todas as possíveis, a infecção é a mais temida, pela possibilidade de alcançar enxertos vasculares e provocar sua rotura ou trombose, causar a deiscência de suturas no coração ou vasos, promover a contaminação e infecção em próteses intracardiacas e, até mesmo, levar a um quadro séptico, colocando em risco a vida dos pacientes.

Várias hipóteses têm sido aventadas como causa da infecção: a via hematogênica, o uso excessivo de agentes que obstruam a medula óssea (cera de osso), utilização inadequada do eletrocautério e a secçāo incorreta do esterno, provocando fraturas. Também as cirur-

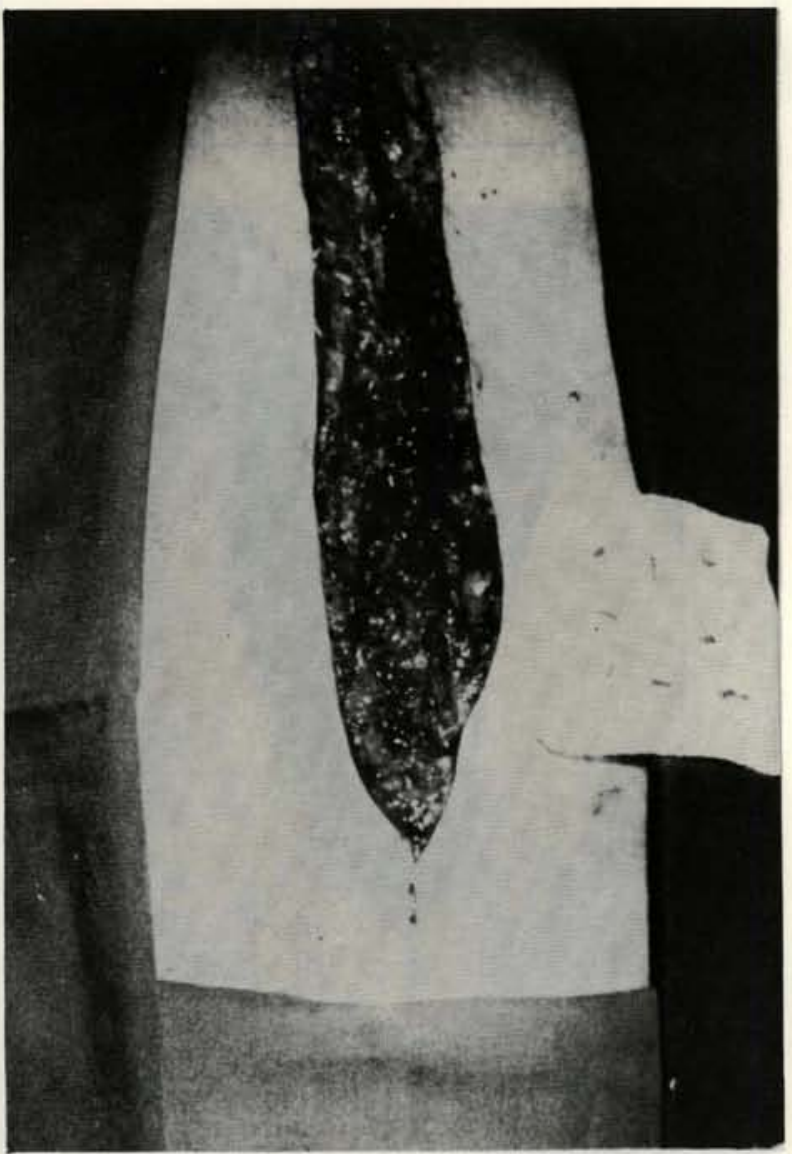

Fig. 1 - Retirada de fios de sutura no desbridamento de um dos casos gias com duração prolongada, tempo excessivo de circulação extracorpórea, sangramento pós-operatório que necessite reexploração, massagem cardiaca externa, síndrome de baixo débito, ventilação mecânica prolongada e dissecção da AMIE são citados como causas $\operatorname{associadas}^{4,7,12}$.

Em nosso material, a dissecção da AMIE parece ter, efetivamente, contribuído para aumentar a incidência de infecçāo, pois estava presente em seis dos sete casos estudados $(85,7 \%)$. A síndrome de baixo débito em três casos $(42,8 \%)$ aparece, a seguir, como fator associado mais freqüente e os demais têm pequena representatividade, conforme já mostramos anteriormente.

O diagnóstico precoce da infecção e o tratamento imediato e agressivo nos parecem ser a chave do sucesso na condução destes casos. Em nossos pacientes, os sintomas mais comuns foram a hiperemia local acompanhada de dor e febre, seguida pela secreção purulenta e instabilidade óssea.

Até o início desta série, tratávamos os pacientes com infecção esternal pela técnica de SHUMAKER Jr. \& MANDELBAUM ${ }^{16}$, que consiste no desbridamento ósseo, instalação de um sistema de irrigação contínua com solução antibiótica e ressutura do osso e tecidos moles. Infelizmente, os resultados eram desanimadores $\mathrm{e}$ a infecção se mantinha, na maioria dos casos, em função de um desbridamento ósseo insuficiente, já que o receio de ficarmos com uma área muito extensa a ser coberta nos limitava.

Iniciando em outubro de 1986, a partir dos resultados de ARNOLD \& PAIROLERO1, 2, 10, 11 e animados com os resultados que observamos em pacientes com osteomielite de membro inferior tratados com transposição de retalhos musculares, passamos a tratar os pacientes com infecção do esterno em conjunto com o Serviço de Cirurgia Plástica da Santa Casa de Misericórdia de Marília.

Desde então, convencidos da importância de se levar tecido com irrigação abundante ao foco de infecçāo, após a limpeza deste, procuramos estabelecer uma rotina de atendimento. Nesta rotina, assim que definimos o diagnóstico, o paciente é submetido a uma limpeza, sob anestesia geral, da forma mais completa possível, não permitindo que permaneça qualquer resto de tecido necrótico, com especial ênfase aos tecidos ósseos e cartilagens. Concomitantemente, uma veia central é cateterizada e a antibioticoterapia sistêmica, orientada pelo antibiograma, é iniciada. A área cruenta é mantida aberta e dois a três curativos com iodo povidine são realizados diariamente. Esta medida nos permite acompanhar a granulação tecidual, ao mesmo tempo em que cuidamos da manutençāo do estado geral destes pacientes, associando, se necessário, suporte nutricional, como ocorreu em um dos nossos casos. No instante em que uma boa granulação é obtida, o paciente é reoperado, para cobertura da área exposta pelo desbridamento. 
BARROS, R. T.; MARCHI, M. A.; GUIMARĀES FILHO, F. V.; SILVEIRA, W. F.; JIMENEZ, H. V. C.; PENNA JÚNIOR, A. - Infecçőes do esterno pós revascularização do miocárdio: tratamento com retalhos miocutâneos e musculares. Rev. Bras. Cir. Cardiovasc., $4(2): 151-158,1989$.

A escolha do tipo de retalho é baseada na extensão da ressecçăo óssea e análise da irrigação arterial da musculatura. Assim tivemos:

1) Um caso, que necessitou pequeno desbridamento do esterno, sem atingir as cartilagens costais; a correção foi possível através de descolamento fáscio-cutâneo e sutura direta.

2) Três casos, que exigiram uma ressecção maior do esterno, porém permanecendo ainda parte do mesmo; a reparação foi realizada através de retalhos miocutâneos do músculo peitoral maior, deslizamento medial e aproximaçāo por sutura direta (Figuras 2, 3 e 4).

3) Nos casos restantes (três), a ressecção do esterno foi quase total, atingindo, ainda, as cartilagens costais e parte das costelas (Figura 5). Nestes pacientes, a área exposta é muito grande e se torna necessária a utilização de retalhos musculares. Como os pacientes tiveram dissecção da AMIE, o músculo reto do abdome esquerdo não pôde ser utilizado, já que, para permitir sua rotação para o tórax, o seu pedículo distal tem que ser ligado. A dissecção do músculo peitoral maior pode lesar ramos perfurantes para a AMIE e, assim, reduzir a vascularização para a artéria epigástrica superior que irriga o músculo reto do abdome. Em razão deste fato, a utilização do músculo peitoral maior direito não é recomendável. Optamos, então, pela utilização dos músculos peitoral maior esquerdo e reto do abdome direito. $\mathrm{O}$ primeiro tem seu pedículo vascular dominante mantido através da artéria tóraco-acromial; a dissecção é efetuada a partir da borda esternal, em direção à axila, onde se faz a secção do tendão umeral através de pequena incisão. O reto do abdome é nutrido às custas da artéria epigástrica superior e, após ser desinserido na sua origem, é rodado para o tórax (Figura 6).

Após dissecção e liberação, os músculos são transpostos para cobrir a área exposta, fixando-se suas extremidades aos bordos ósseos remanescentes. O tecido subcutâneo e a pele são aproximados de forma habitual, com monofilamento inabsorvível (Figura 7).

Os resultados estético e funcional foram considerados ótimos, pois, após a fase de cicatrização, uma estrutura firme recobriu a face anterior do tórax. Não há déficit funcional para o membro superior e a possibilidade de ocorrer hérnia abdominal é pequena, pois a bainha anterior do reto é fechada (Figura 8 ).

A análise dos casos por nós tratados nos leva às seguintes conclusōes, que estão de acordo com a maioria dos autores:

1) A recorrência da infecção, na maioria dos casos, é funçāo de desbridamento incompleto.

2) A oclusāo do espaço morto criado pela ressecção óssea deve ser realizada com tecido bem irrigado; no caso, o tecido muscular.

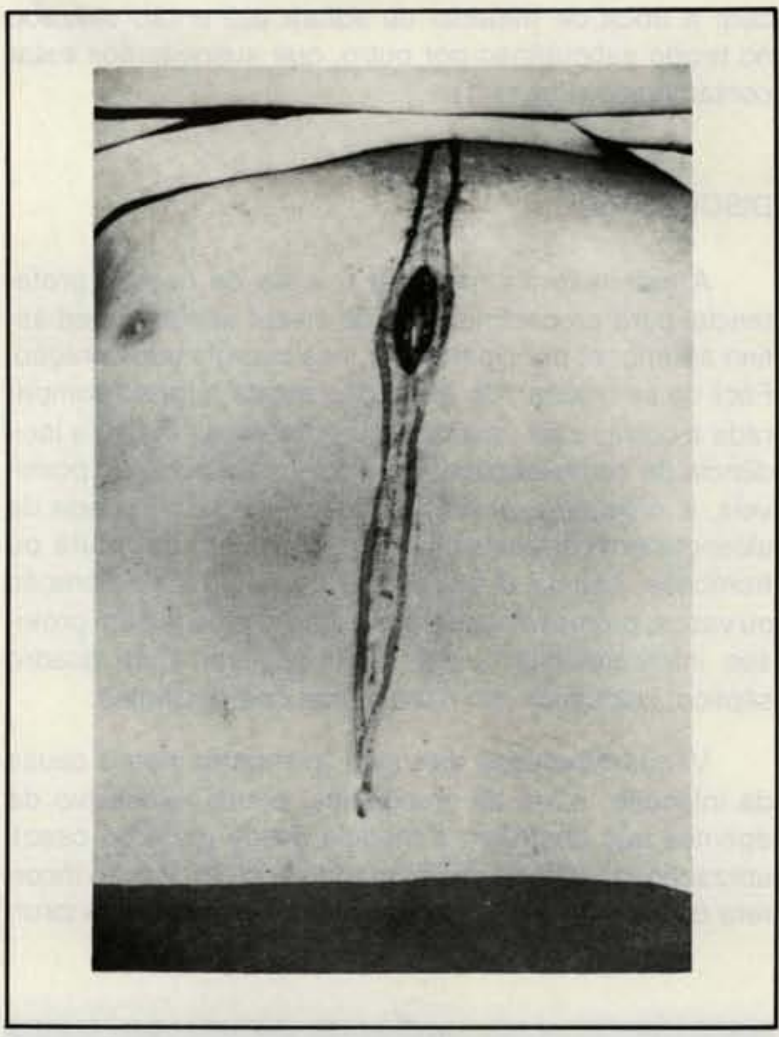

Fig. 2 - Aspecto pré-desbridamento inicial.

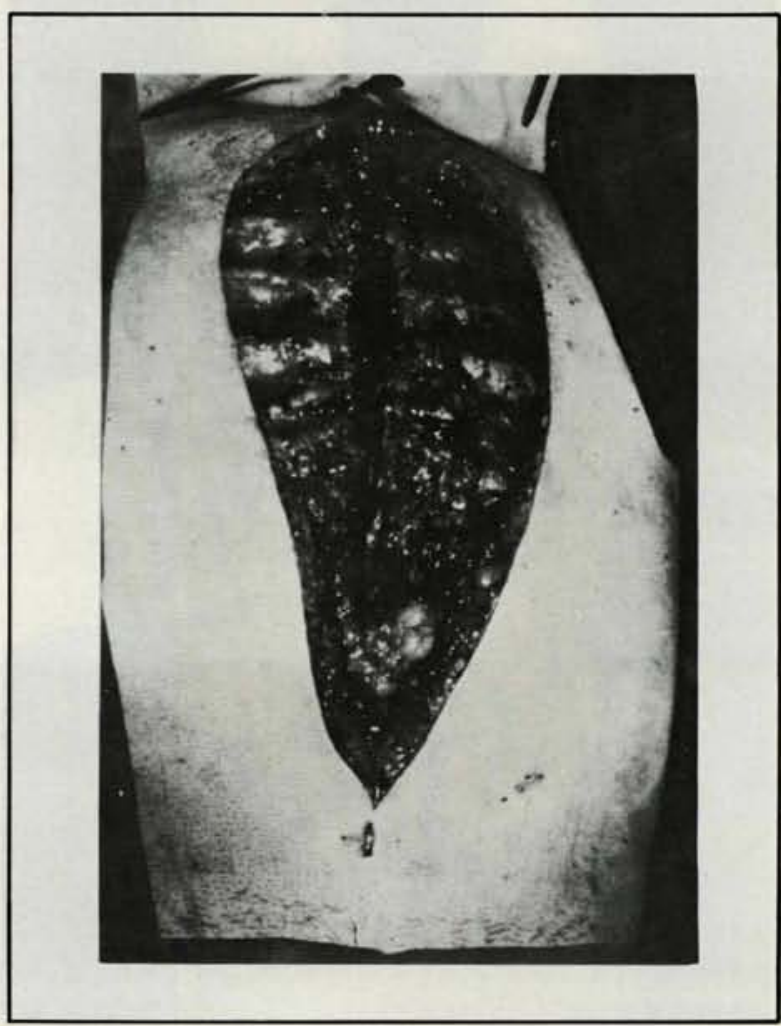

Fig. 3 - Aspecto após descolamento miocutâneo bilateral. 
BARROS, R. T.; MARCHI, M. A.; GUIMARĀES FILHO, F. V.; SILVEIRA, W. F.; JIMENEZ, H. V. C.; PENNA JÚNIOR, A. - Infecçōes do esterno pós revascularização do miocárdio: tratamento com retalhos miocutâneos e musculares. Rev. Bras. Cir. Cardiovasc., 4(2): 151-158, 1989.

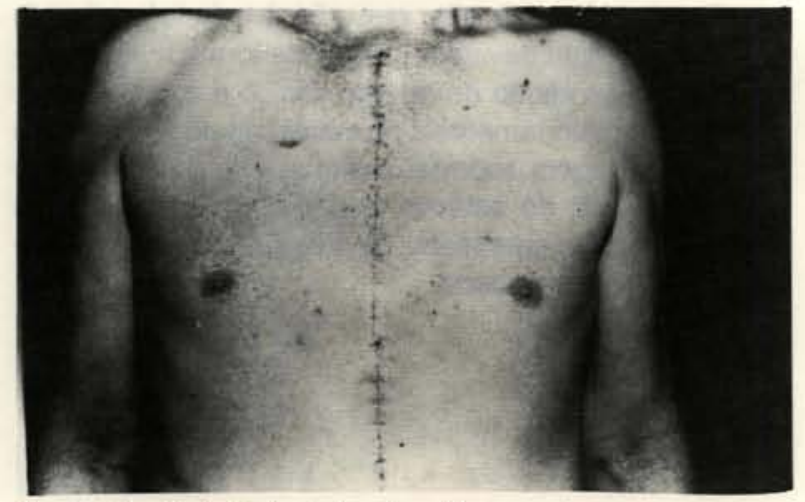

Fig. 4 - Resultado final; retalho miocutâneo.

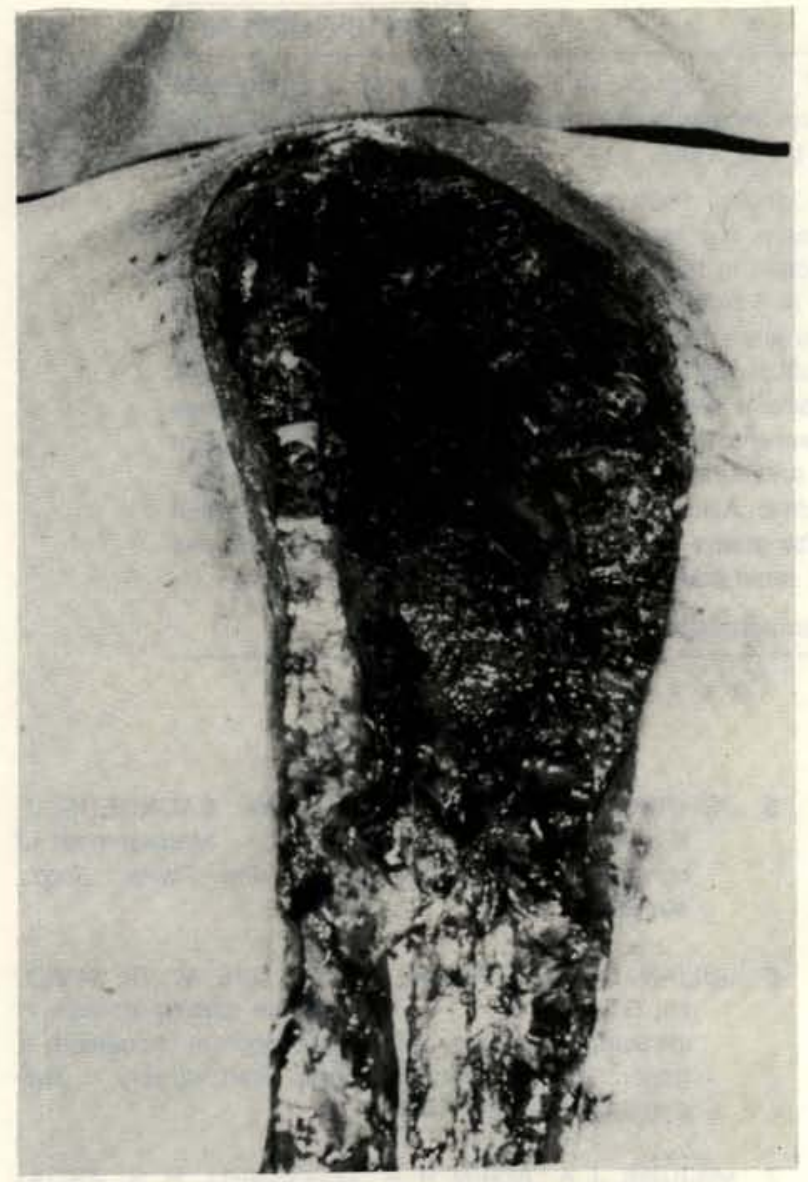

Fig. 5 - Extensa ressecção do esterno e cartilagens costais.

3) Esta conduta contribuiu, efetivamente, na redução da morbi-mortalidade nos casos de infecçāo pós-operatória do esterno, propiciando acentuada redução no tempo de internação e conseqüente queda dos gastos relativos ao tratamento.

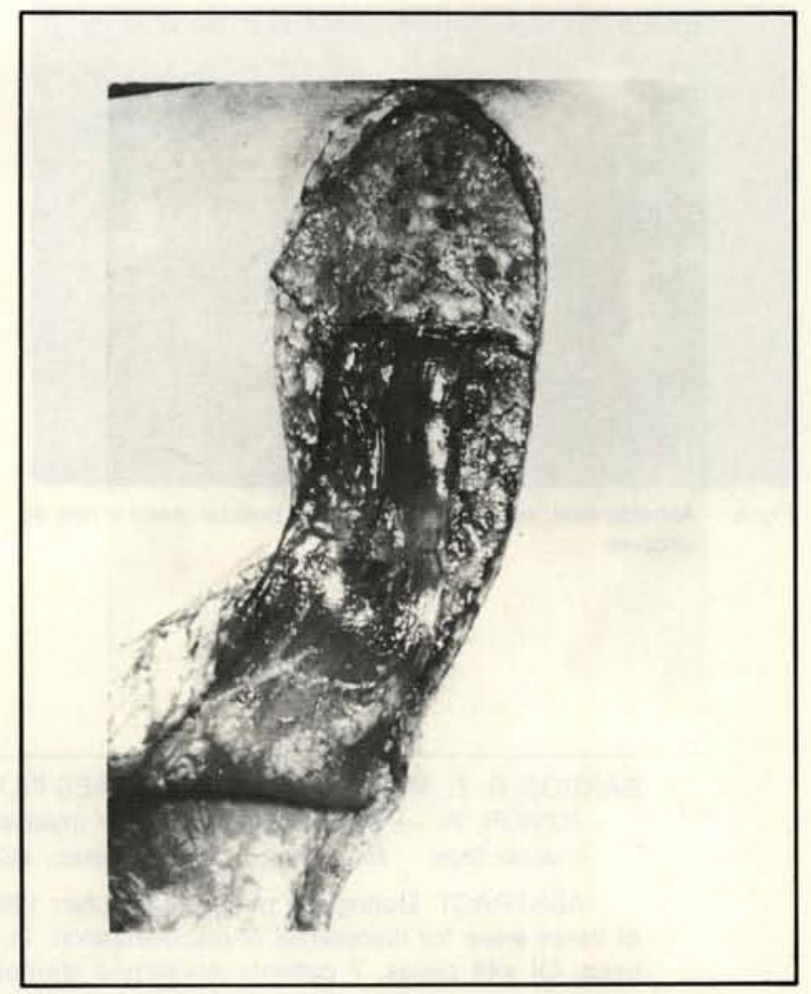

Fig. 6-Após dissecção dos músculos, a área é coberta pelo avanço do peitoral maior e rotaçāo do reto do abdome.

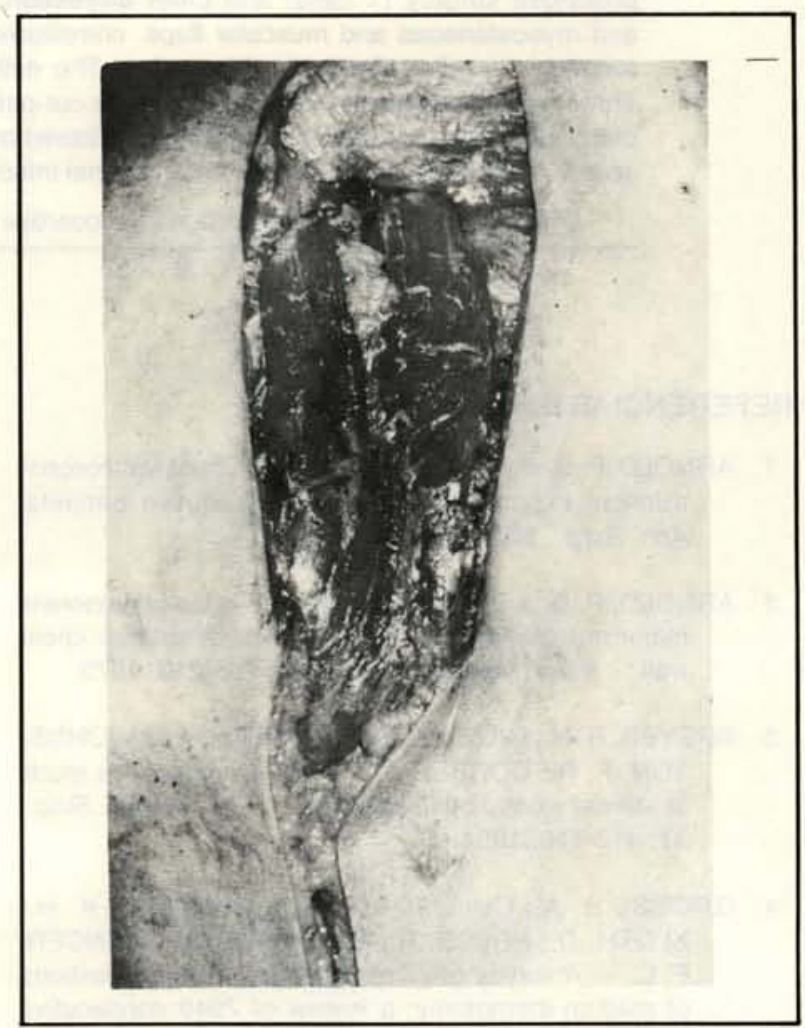

Fig. 7 - Após a sutura da incisâo abdominal, inicia-se a sutura do tecido subcutâneo do tórax. 
BARROS, R. T.; MARCHI, M. A.; GUIMARÃES FILHO, F. V.; SILVEIRA, W. F.; JIMENEZ, H. V. C.; PENNA JÚNIOR, A. - Infecçōes do esterno pós revascularização do miocárdio: tratamento com retalhos miocutâneos e musculares. Rev. Bras. Cir. Cardiovasc., 4(2): $151-158,1989$.

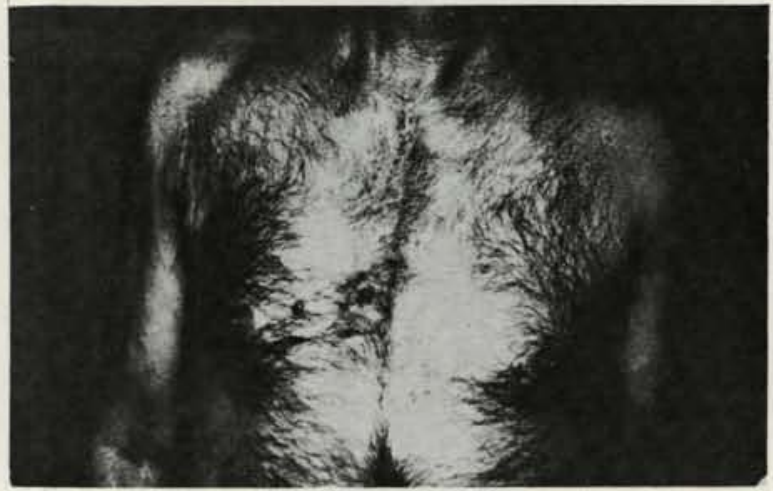

Finalizando, vale citar que não é toda infecção em esternotomia que deve ser tratada de forma mais agressiva. A apresentação do quadro clínico e a experiência do grupo são fundamentais na indicação de um ou outro tipo de abordagem; todavia, assim que for diagnosticado o envolvimento do esterno, é imperiosa uma conduta mais precoce e agressiva, de acordo com a sistematização aqui preconizada.

Fig. 8- Aspecto final; após retalho muscular peitoral maior e reto do abdome.

RBCCV 44205-86

BARROS, R. T.; MARCHI, M. A.; GUIMARÃES FILHO, F. V.; SILVEIRA, W. F.; JIMENES, H. V. C.; PENNA JÚNIOR, A. - Sternal infections after myocardial revascularization: treatment by myocutaneous and muscle flaps. Rev. Bras. Cir. Cardiovasc., 4(2): 151-158, 1989.

ABSTRACT: During the period of October 1986 to January 1989 we executed 445 sternotomies; 158 of these were for myocardial revascularization. In 92 cases the left internal mammary artery (LIMA) was used. Of 445 cases, 7 patients developed sternal infection in the immediate post operative period. The average time for the infection to appear was 8.7 days (4-15 days). Of these, 6 patients were male with an average age of 48.8 years (35-60 years). All cases were first operations; complicating factors were diabetes (1 case), pulmonic emboly with respiratory insufficiency (1 case), low output syndrome ( 3 cases), prolonged surgery ( 1 case) and LIMA dissection (6 cases). With the use of plastic surgery techniques and myocutaneous and muscular flaps, complications were corrected and permitted a more rapid patient recovery, avoiding deaths in this period. The esthetic and functional results were considered excellent. Three small dehiscences were treated in the out-patient clinic. Also of great importance was the identification of the germes by cultures and the treatment based on antibiograms in conjunction with the surgical techniques aplied. In conclusion, we judged that in sternal infections, rapid and aggressive surgery avoided deaths.

DESCRIPTORS: sternal infections; myocardial revascularization, complications.

\section{REFERÊNCIAS BIBLIOGRÁFICAS}

1 ARNOLD, P. G. \& PAIROLERO, P. C. - Chest wall reconstruction: experience with 100 consecutive patients. Ann. Surg., 100: 725-731, 1984.

2 ARNOLD, P. G. \& PAIROLERO, P. C. - Use of pectoralis major muscle flaps to repair defects of anterior chest wall. Plast. Reconstr. Surg., 63: 205-213, 1979.

3 BREYER, R. H.; MILLS, S. A.; HUDSPETH, A. S.; JOHNSTON. F. R.; CORDELL, A. R. - A prospective study of sternal wound complications. Ann. Thorac. Surg., 37: 412-416, 1984.

4 GROSSI, E. A.; CULLIFORD, A. T.; KRIEZER, K. H.; KLOTH, D.; PRESS, R.; BAUMANN, G.; SPENCER, F. C. - A survey of 77 major infections complications of median sternotomy: a review of 7949 consecutive operative procedures. Ann. Thorac. Surg., 40: 214-223, 1985.
5 JOHNSON, P.; FREDERIKSEN, J. W.; SAUNDERS, J. H.; LEWIS, V.; MICHAELIS, L. L. - Management of chronic sternal osteomyelites. Ann. Thorac. Surg., 40: $69-72,1985$

6 JULIAN, O. C.; LOPEZ-BELLO, M.; DYE, W. S.; JAVID, H.; GEOVE, W. J. - The median sternal incision in intracardiac surgery with extracorporeal circulation: a general evaluation of its use in heart surgery. Surgery, 42: 753-761, 1957.

7 MAJURE, J. A.; ALBIN, R. E.; O'DONNELL, R. S.; ARGANESE, T. J. - Reconstruction of the infected median sternotomy wound. Ann. Thorac. Surg., 42: 9-12, 1986.

8 NAHAI, F.; MORALES Jr., L.; BONE, D. K.; BOSTIWICK III, J. - Pectoralis major muscle turnover flaps for closure of the infected sternotomy wound with preservation of form and function. Plast. Reconstr. Surg., 70: $471-474,1982$. 
BARROS, R. T.; MARCHI, M. A.; GUIMARÃES FILHO, F. V.; SILVEIRA, W. F.; JIMENEZ, H. V. C.; PENNA JÚNIOR, A. - Infecçōes do esterno pós revascularização do miocárdio: tratamento com retalhos miocutâneos e musculares. Rev. Bras. Cir. Cardiovasc., 4(2): 151-158, 1989.

9 OTTINO, G.; DE PAULIS, R.; PAUSIERI, S.; ROCCA, G.; TALLONE, M. V.; COMOGLIO, C.; COSTA, P.; ORZAN, F.; MOREA, M. - Major sternal wound infection after open-heart surgery: a multivariate analysis of risk factors in 2579 consecutive operative procedures. Ann. Thorac. Surg., 44: 173-179, 1987.

10 PAIROLERO, P. C. \& ARNOLD, P. G. - Management of infected median sternotomy wounds. Ann. Thorac. Surg., 42: 1-2, 1986.

11 PAIROLERO, P. C. \& ARNOLD, P. G. - Management of recalcitrant median sternotomy wounds. J. Thorac. Cardiovasc. Surg., 88: 357-364, 1984.

12 SARLLY, H. E.; LECLERC, Y.; MARTIN, R. D.; TONY, C. P.; GOLDMAN, B. S.; WEISWL, R. D.; MICKLEBORONGH, L. L.; BAIRD, R. J. - Comparison between antibiotic irrigation and mobilization of pectoral muscle flaps in treatmerit of deep sternal infections. $J$. Thorac. Cardiovasc. Surg., 90: 523-531, 1985.

13 SARR, M. G.; GOTT, V. L.; TOWNSEND, T. R. - Mediastinal infection after cardiac surgery. Ann. Thorac. Surg., 38: 415-423, 1984.

14 SERRY, C.; BLECK, P. C.; JAVID, H.; HUNTER, J. A.; GOLDIN, M. D.; DELANIA, G. A.; NAJAFI, H. - Sternal wound complications: management and results. $J$. Thorac. Cardiovasc. Surg., 80: 861-866, 1980.

15 SHAFIR, R.; WEISS, J.; HERMAN, O.; COHEN, N.; STERN, D.; IGRA, Y. - Faulty sternotomy and complications after median sternotomy. J. Thorac. Cardiovasc. Surg., 96: 310-313, 1988.

16 SHUMACKER Jr., H. B. \& MANDELBAUM, I. - Continuous antibiotic irrigation in the treatment of infection. Arch. Surg., 86: 384-387, 1963.

17 STONEY, W. S.; ALFORD Jr., W. C.; BURRUS, G. R.; FRIST, R. A.; THOMAS Jr., C. S. - Median sternotomy dehiscence. Ann. Thorac. Surg., 26: 421-426, 1978.

\section{Discussão}

\section{DR. ALTAMIRO RIBEIRO DIAS \\ São Paulo, SP}

Inicialmente, queremos agradecer à Comissão Organizadora, pelo honroso convite para comentarmos o belo trabalho apresentado pelo $\mathrm{Dr}$. Rubens de Barros e seu colaboradores. Achamos muito interessante a técnica desenvolvida e que foi empregada nos sete casos estudados. Em nossa experiência, o sucesso no manejo cirúrgico dos pacientes com infecção do esterno pós-operatória depende, basicamente, dos fatores subjacentes à infeção e à precocidade da intervenção. Essa complicação tem sido mais freqüente nos pacientes com síndrome de baixo débito, associada a insuficiência res- piratória e complicaçōes neurológicas. São aqueles doentes com intubação endotraqueal prolongada, que não conseguem livrar-se do respirador e que evoluem com complicações de múltiplos órgãos. Nesse grupo especialmente grave de pacientes, ao menor sinal de infecção do esterno, a intervenção deve ser imediata. Temos realizado remoçăo de fragmentos ósseos, a mais extensa, para deixar-se somente osso com boas condiçōes de vitalidade e sem infecção. Para reconstrução, não sentimos, ainda, necessidade do implante de retalhos miocutâneos. Durante vários anos, utilizamos para a reconstução o emprego de cintas metálicas, de 5 por $12 \mathrm{~mm}$, as quais eram passadas por fora do remanescente do esterno e tracionando-se para a linha média os dois cabos da cinta, fazia-se a aproximaçāo em bloco do plano ósteo-muscular. Após adequadamente posicionada, essa cinta era fixada com um fio de aço, mantendo-se em posição. Mais recentemente, temos feito essa fixação com múltiplos fios de aço, sem problemas. Quando necessário, podemos manter o mediastino sob lavagem com soros e antibióticos. Paralelamente ao tratamento local da complicaçāo, sāo tomadas as medidas gerais que o caso exigir. Discordamos do fato que a utilizaçăo da artéria mamária esquerda possa influir no favorecimento dessa complicação. De dato, dos primeiros 96 casos de utilização de dupla mamária, tivemos apenas um deiscência de esterno, a qual independeu desta dissecção. O emprego de dupla mamária tem sido rotineiro, sem haver qualquer incremento dos casos de infecção do esterno e/ou mediastino. Gostaria de perguntar se o laboratório produtor do material de sutura, supostamente contaminado, foi alertado e se o lote suspeito foi submetido a estudos para comprovar se não houve a possibilidade aventada.

\section{DR. CÉSAR A. CONFORTI Santos, SP}

Primeiramente, gostaria de agradecer à Comissão Organizadora, em meu nome e no da Santa Casa de Misericórdia de Santos, o privilégio de comentar tão importante trabalho. Em levantamento efetuado em nosso Serviço, pudemos observar os seguintes dados: a partir de julho de 1987 , foram realizadas 392 cirurgias, das quais 155 eram de revascularização do miocárdio isolada, onde tivemos cinco casos $(3,2 \%)$ de deiscência de esterno tendo sido dissecada a mamária em dois dos casos. Acima de 70 anos, foram revascularizados 16 pacientes e, em apenas um, ocorreu deiscência de esterno por traumatopnéia e este paciente era o único no qual não havia sido dissecada a mamária. Concordamos com o Dr. Rubens, quanto aos fatores que predispōem à ocorrência de infecçāo de esterno; porém, em nosso levantamento, não encontramos correlação com o fato de haver sido dissedada a mamária, bem como com o fator etário. Tenho convicção de que, dentre os vários fatores relacionados com a deiscência de esterno, o mais 
BARROS, R. T.; MARCHI, M. A.; GUIMARĀES FILHO, F. V.; SILVEIRA, W. F.; JIMENEZ, H. V. C.; PENNA JÚNIOR, A. - Infecçōes do esterno pós revascularização do miocárdio: tratamento com retalhos miocutâneos e musculares. Rev. Bras. Cir. Cardiovasc., 4(2): 151-158, 1989.

importante é o fator mecânico. A abertura e o fechamento, de forma cuidadosa, do tórax tem importância capital na prevençāo da complicação. Por outro lado, a pronta intervenção, uma vez constatado qualquer comprometimento com a cicatrização ou instabilidade do osso, melhora em muito os resultados, evitando-se a utilização de técnicas mais agressivas, como a apresentada. Tal abordagem deve ser efetuada sempre com o paciente sob anestesia geral, com sangue disponivel para qualquer emergência e, então, após a reabertura, procede-se a amplo debridamento e reavivamento dos bordos. Fecha-se o esterno com reforço de fios de aço dispostos paralelamente aos bordos do esterno, facilitando o apoio dos fios de aço transversais. O tórax é fechado deixando-se sistema de drenagem para irrigação contínua com solução de PVPI. Tal procedimento é mantido por 10 dias, quando, então, retiram-se os drenos. Dessa maneira, temos otbido excelentes resultados porém, não podemos deixar de considerar interessante a técnica descrita para utilizaçāo, isto é, nos casos em que, quando necessário, o esterno, cartilagens e mediastino estejam muito comprometidos. Importante para a prevenção também vem a ser o controle da esterilização do material, assim como a limpeza e desinfecção da sala de cirurgia e UTI, o manuseio adequado do paciente por parte dos médicos e enfermagem, tendo-se o cuidado de lavar as mãos antes de qualquer procedimento, a antibioticoprofilaxia empregada, recomendando-se sua utilização somente por 3 dias, para se evitar resistência bacteriana. Encerrando, gostaria de formular as seguintes perguntas: na revisão da literatura que efetuamos, notamos haver duas atitudes quanto à realização do procedimento. Uma em um único tempo, deixando-se a irrigaçāo contínua; outra, deixando-se o fechamento completo para ser realizado após 10 dias. Qual o critério adotado na escolha do procedimento? O que pensa do tratamento em um único tempo?

\section{DR. ROBERTO GOMES DE CARVALHO Curitiba, $P R$}

Gostaria de cumprimentar o Dr. Barros, pelo tabalho apresentado. Nāo somente na literatura nacional, como internacional, a mediastinite tem uma pequena incidên- cia. O hospital em que trabalhamos (Clínica de Fraturas e Ortopedia XV, Curiba, PR) é especializado em Ortopedia. E nós, os cirurgiōes e ortopedistas, temos muito receio da infecção. Desde o início de nossa experiência, operamos 296 casos com CEC e não tivemos nenhum caso de mediastinite e nem infecção da ferida operatória. Em nossa experiência global na revascularizaçăo do miocárdio, tivemos com 113 casos. Em $80 \%$, foi utilizada a artéria mamária, e em $10 \%$, ambas as artérias mamárias. Desde o início do Serviço até agora, o antibiótico foi utilizado de três maneiras: Grupo I (54\%), cefalotina e gentamicina por 72 horas; Grupo II (25\%), apenas a cefalotina por 72 horas e Grupo III $(20 \%)$ a cefelotina por apenas 24 horas. Gostaria de perguntar ao Dr. Barros qual a incidência de mediastinite em seu Serviço? Qual o tipo de antibiótico empregado e por quanto tempo? Houve algum caso de pericardite constritiva pelo uso de iodo-povidine?

\section{DR. BARROS \\ (Encerrando)}

Em relação às observaçōes dos colegas que comentaram nosso trabalho, iremos, a seguir, sintetizar as respostas: em nossa casuística, de forma concordante com os dados de literatura, houve nítida relação entre utilização da artéria mamária e infecção óssea, sendo que a mesma era mais intensa do lado da dissecção da mamária. Quanto à pergunta referente ao laboratório. não comunicamos oficialmente a nossa suspeita, uma vez que as culturas dos fios foram sempre negativas. A técnica de irrigação contínua nāo foi eficaz, em tentativas anteriores, razão pela qual buscamos outras opções. A possibilidade de efetuar o procedimento em um único tempo é atraente e acreditamos que possa, no futuro, ser o método de escolha. A incidência de mediastinite, no nosso Serviço, gira ao redor de $1 \%$ e utilizamos, de rotina, cefalosporina endovenosa por 72 horas, iniciada 12 horas antes do procedimento. Não tivemos nenhum caso de pericardite constrictiva. Talvez porque o período de utilização de iodobovidine tenha sido muito curto. Agradecemos à Comissão Organizadora deste Congresso e aos colegas que enriqueceram nossa apresentação com seus comentários. 